SCAIDoC

Infer, Interpret \& Inspire Science

\section{A Retrospective Evaluation Of Centric Relation Techniques Used In Different Edentulous Conditions For A Temporary Partial Denture Fabrication}

Research Article

\author{
M. Sai Teja Reddy ${ }^{1}$, L. Keerthi Sasanka ${ }^{2 *}$
}

${ }^{1}$ Department of Prosthodontics, Saveetha Dental College And Hospitals, Saveetha Institute Of Medical and Technical Sciences, Saveetha University, Chennai, 600050, India.

${ }^{2}$ Department of Prosthodontics, Saveetha Dental College and Hospitals, Saveetha Institute Of Medical And Technical Sciences, Saveetha University, Chennai, India.

\title{
Abstract
}

The aim of this study was to retrospectively evaluate the commonly used technique for recording centric relation in temporary partial denture cases among dental students. A total of 820 data entries were taken, duplicate and missing entries were omitted. So a total of 665 entries were evaluated. The data was collected from patient records in Saveetha Dental College, over a period of one year. The evaluation was based on the technique used by the dental students, to record centric relation for temporary partial denture cases. The results of the study were subjected to statistical analysis. Data analysis was done using SPSS software version 23.0.Chi-square test and frequency evaluation was done to evaluate the most frequently used method to record centric relation. It was found that about $93.08 \%$ of the dental students have used the pressure method and $6.92 \%$ of them have used the pressure less method. $(\mathrm{P}$ value $=.001)$ and found to be statistically significant. The present study concluded that most of the dental students preferred the pressure method to record Centric Relation while fabricating a temporary partial denture.

Keywords: Technique To Record Centric Relation; Qualification Of The Clinician; Age Of The Patient; Gender Of The Patient And Missing Teeth.

\section{Introduction}

The Glossary of Occlusal Terms2 states that "centric relation is an anatomically and physiologically stable, repeatable posture of the mandible. Recording correct centric is an important method for the success of the treatment, this is set forth by Tench, Tuckfiels, and Block [21]. Teeth and the joints are a part of a functional unit that must be considered together. All parts of the masticatory system are interrelated and for por equilibrium all these should work in harmony both anatomically and functionally. It is also considered the most acceptable treatment and reference position. It is the normal static relation of the mandible to the maxillae, the glenoid fossa, and the neuromuscular mechanism. The position is three dimensional, including height (vertical), width (lateral) and depth (horizontal).

Centric relation is the horizontal relation usually utilized for diagnosis, occlusion analysis and full mouth rehabilitation cases. It is a reproducible maxillo-mandibular relation important to the comfort, function and health of the stomatognathic system [12]. Due the fact that the CR is a determined position by the temporomandibular joint, it is fundamental that no muscular activity interferes in the mandibular position and, therefore, all neuroprotector reflexes must be avoided during registration $[37,26,11]$.

The concept of CR is controversial in dentistry and its definition has changed over the years. The academy of Prosthodontists defines CR as 'The maxillomandibular relationship in which the condyles articulate with the thinnest avascular portion of their respective disks with the condyle in the anterior-superior position against the slopes of the articular eminence. This position is independent of teeth contact'. Dawson described CR as the most comfortable and stable position of the jaw, in which the joints can be subjected to load without causing discomfort Dawson PE. New definition for relating occlusion to varying conditions of the temporomandibular joint [13].

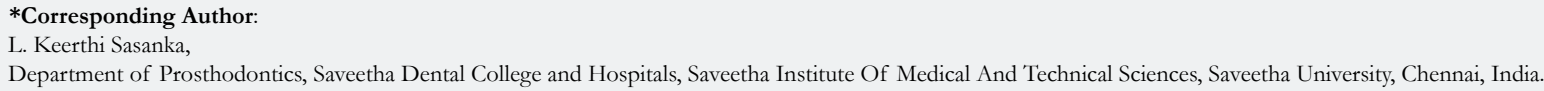

Citation: M. Sai Teja Reddy, L. Keerthi Sasanka. A Retrospective Evaluation Of Centric Relation Techniques Used In Different Edentulous Conditions For A Temporary Partial Denture Fabrication. Int J Dentistry Oral Sci. 2020;S5:02:0024:134-139. doi: http://dx.doi.org/10.19070/2377-8075-SI02-050024

Copyright: L. Keerthi Sasanka 2020 . This is an open-access article distributed under the terms of the Creative Commons Attribution License, which permits unrestricted use, distribution and reproduction in any medium, provided the original author and source are credited. 
Celenza says that there could be several CR positions acceptable. Serrano supports this statement by indicating that CR is not only a position, but a range of positions [31]. Dental rehabilitation and prosthesis require the diagnosis and registration by the vertical dimension, centric relation, functional areas, and a torsion-free maxillo- mandibular relation.

Terminology in the field of CR has been confusing as a result of changes in definition. The Glossary of Prosthodontic Terms is the publication of the Academy of Prosthodontics (formerly Academy of Denture Prosthetics) and is updated every 6 years. There have been six updates since its first publication in the Journal of Prosthetic Dentistry (Glossary of Prosthodontic Terms, 1956). This Glossary has served as the dictionary standard for terms used in dentistry,particularly prosthodontics, since 1956.

Centric relation is considered the most acceptable treatment position, but a clinical centric relation is not accepted as reliable until all of the tissues involved in mandibular movement have been stabilized with prolonged function. For assessing the validity of centric relation, various methods have been suggested. Repeatability is one of the important criteria for accepting a centric relation record. Centric relation is the point where the hinge axis is constant for both the maxilla and the mandible. It is the position where the mandible revolving around the hinge axis, in which the opening and closing with pure rotary movements in a vertical plane and is the only position in which pure rotary movement will occur by gliding of the meniscus upon the fossa.

The objective of recording centric is to establish the relationship of the teeth to the axis in the terminal position of the condyles, the position in which the chewing stroke ends. Since the axis is constant to the mandibular teeth in every eccentric position and constant to both the mandibular and maxillary teeth only in centric relation,the axial relations of the teeth will be correct in every masticating position. - ernest garner.

There are various methods to record centric relation.They are Pressure method, Pressure less method, Inter occlusal check record, Needle house method, Patterson method, Graphic methods (intraoral and extraoral) and Radiographic method.

Many studies which involved case reports [4], surveys [5], systematic reviews [16, 3, 25], literature reviews [35, 36, 15, 32, 36, 30], In Vivo studies [24, 22, 14], In vitro studies [15, 2] and retrospective studies [6] were carried out by our team previously. We are currently focusing on epidemiological studies. The main objective of this study was to evaluate which type of centric relation method is frequently used by the dental clinicians in an institutional setting.

\section{Materials and Methods}

\section{Sample Collection}

A total of 1020 patient data were taken from 86000 of patient data after reviewing, duplicate and missing entries were omitted. So a total of 665 entries were evaluated. The data was collected from the patient database of saveetha dental college between 01 June 2019 and 31 march 2020. Samples with improper data and repetitions were excluded from the study and ethical approval was done by the institutional review board (SDC/SIHEC/2020/DIASDATA/0619-0320). The data is then arranged and checked for the frequency of different methods used for recording centric in temporary partial dental cases.

Inclusion Criteria - Partially edentulous patients and patients with informed consent.

Exclusion Criteria - Patients without informed consent, patients with digitally designed and milled partial dentures and complete edentulous cases

\section{Statistical Analysis}

Data analysis was done using SPSS software. Frequency evaluation and Chi-square test was done to evaluate the centric relation technique used in different edentulous conditions

Dependable variables include the type of centric recording technique used, Age, Arch, location of tooth loss and the practitioner.

Independent variables the type of material used and the technique of fabrication.

\section{Result And Discussion}

From the retrospective study, the highest frequency of method used to record centric is the pressure method. Out of 665 collected data 636 were undergraduate students and 29 were postgraduate students and the percentage of undergraduate and postgraduate students are $95.64 \%$ and $4.36 \%$ respectively (figure1).

Out of it 619 members were using pressure method and 46 members were using pressure less (nick and notch) method (Table1).

Figure 1. The pie diagram showing the total percentage of undergraduate and postgraduate students performed to record centric relations. Undergraduate students $-95.64 \%$, was more when compared to postgraduates $-4.36 \%$.

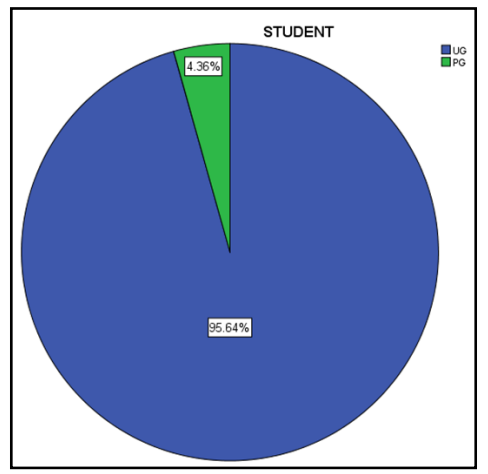


Percentage wise it is shown as $93.08 \%$ of them have used the pressure method and $6.92 \%$ of them used pressure less technique (figure2). Among the students who were using pressure technique, 602 were undergraduate students and 17 were postgraduate students. And in pressure less technique 34 were undergraduate students and 12 were postgraduate students.(figure3). Association between students and the frequency of using a particular technique was done using (Chi square test - 55.929 and P value $=.001)$ found to be statistically significant.

The total number of missing teeth reported in the upper arch is 323, 322 in lower arch, 20 in both arches (Figure4) and the percentages were $48.6 \%, 48.4 \%$ and $3 \%$ simultaneously. (Table2)

Correlation among the age - frequency of missing teeth, arch wise - frequency and arch - age.

From age wise $>45$ age group reported the highest number of missing cases with count of 480, followed by 36-45 age group with a count of 159 , and least count of 26 was reported in the 18-35 age group.(Table3)

Upper arch and lower arch has been reported the number of missing teeth with slight less numbers in lower arch. Least count was seen in both arches. The frequencies are 323,322 and 20 respectively. In the upper arch, the highest count is seen in the $>45$ age group with a count of 232 followed by 77 in the 36-45 age group then there is a drastic decrease in count from 77 to 14 in the 18-35 age group. In the lower arch, the highest count is seen in the $>45$ age group with a count of 233 followed by 79 in the 36-45 age group and least 10 in the 18-35 age group. In both arch missing cases, the highest frequency is seen in the $>45$ age group, 3 in the 36-45 age group and 2 in the 18-35 age group.Association between age and the number of missing teeth in each arch was done using Chi square test $(\mathrm{p}$ value $=.811)$ and found to be

Table 1: shows the association between the students (UG \& PG) and frequency of using different techniques to record centric relations. Pressure method was used more frequently by undergraduates (UG) than pressure less method.Association between students and the frequency of using a particular technique was done using (Chi square test $-\mathbf{5 5 . 9 2 9}$ and $P$ value $=$ .001) found to be statistically significant.

\begin{tabular}{|c|c|c|c|c|}
\hline & \multicolumn{2}{|c|}{ STUDENT } & \multirow[b]{2}{*}{ Total } & \multirow{5}{*}{$\begin{array}{c}\text { Pearson chi-square value }-55.929 \\
\text { P value }-0.001\end{array}$} \\
\hline TECHNIQUE & UG & PG & & \\
\hline PRESSURE TECHNIQUE & 602 & 17 & 619 & \\
\hline PRESSURE LESS TECHNIQUE & 34 & 12 & 46 & \\
\hline Total & 636 & 29 & 665 & \\
\hline
\end{tabular}

Figure 2. The pie diagram shows the percentage of students using different techniques to record centric relations. Pressure method $-93.08 \%$ was used more frequently than pressure less method $-6.92 \%$.

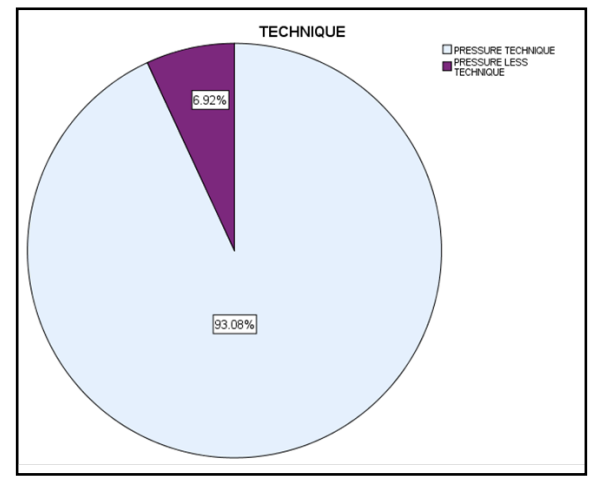

Figure 3. The bar diagram shows the association between the students and frequency of using different techniques to record centric relations. $\mathrm{X}$ axis represents the Students with undergraduates and postgraduates and $\mathrm{Y}$ axis represents the total number of reported cases with technique used to record centric relations. Association between students and the frequency of using a particular technique was done using Chi square test $(P$ value $=.001)$ and found to be statistically significant and most of the students have used pressure method for recording centric relation.

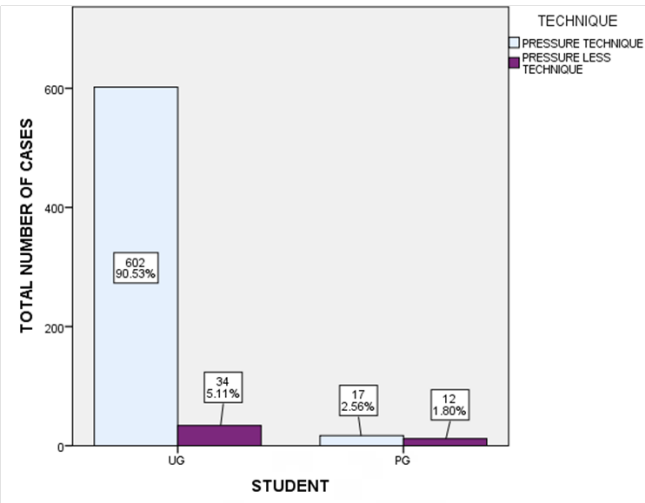


Figure 4. The pie diagram showing the frequency of cases reported with missing teeth in different arches. Highest frequency of missing teeth was seen in the upper arch followed by the lower arch and least with both arch.

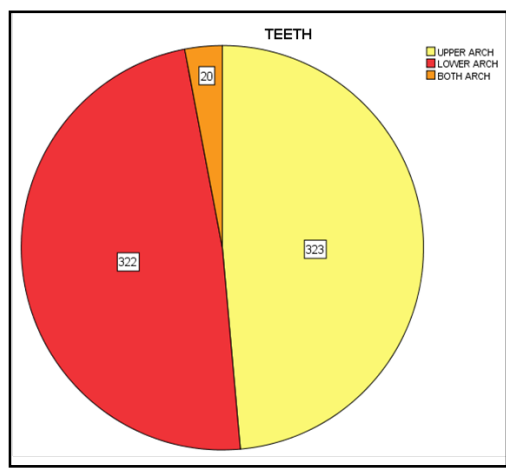

Table 2. The table showing the frequency of cases reported with missing teeth in different arches. Highest frequency of missing teeth was seen in the upper arch followed by the lower arch and least with both arch.

\begin{tabular}{|c|c|c|}
\hline $\begin{array}{c}\text { MISSING TEETH } \\
\text { (ARCH) }\end{array}$ & FREQUENCY & PERCENT \\
\hline UPPER ARCH & 323 & 48.6 \\
\hline LOWER ARCH & 322 & 48.4 \\
\hline BOTH ARCH & 20 & 3 \\
\hline TOTAL & 665 & 100 \\
\hline
\end{tabular}

Table 3. The table shows association between the age group and number of cases reported with missing teeth in different arches: Association between age groups and the number of missing teeth in each arch was done using Chi square test (ChiSquare Value $=3.325, \mathrm{p}$ value $=.811)$ and found to be statistically not significant and found that most of the missing tooth cases reported in.

\begin{tabular}{|c|c|c|c|c|c|}
\hline \multirow[b]{2}{*}{ AGE } & \multicolumn{3}{|c|}{ TEETH } & \multirow[b]{2}{*}{ TOTAL } & \multirow{6}{*}{$\begin{array}{c}\text { Pearson chi-square value }-3.325 \\
\text { P value }-0.811\end{array}$} \\
\hline & $\begin{array}{l}\text { UPPER } \\
\text { ARCH }\end{array}$ & $\begin{array}{l}\text { LOWER } \\
\text { ARCH }\end{array}$ & $\begin{array}{l}\text { BOTH } \\
\text { ARCH }\end{array}$ & & \\
\hline $18-35$ & 14 & 10 & 2 & 26 & \\
\hline $36-45$ & 77 & 79 & 3 & 159 & \\
\hline$>45$ & 232 & 233 & 15 & 480 & \\
\hline TOTAL & 323 & 322 & 20 & 665 & \\
\hline
\end{tabular}

Figure 5. The bar graph shows the association between different age groups and the frequency of cases reported. The $X$ axis represents age (18-35years;36-45years;above 45 years) and the $Y$ axis represents the frequency of cases reported with missing teeth in different arches: upper arch; lower arch; and both arches. Association between age groups and the number of missing teeth in each arch was done using Chi square test (Chi-Square Value $=3.325$, $\mathrm{p}$ value $=.811$ ) and found to be statistically not significant. However in the age group above 45 years the highest frequency of missing teeth was seen in the lower arch.

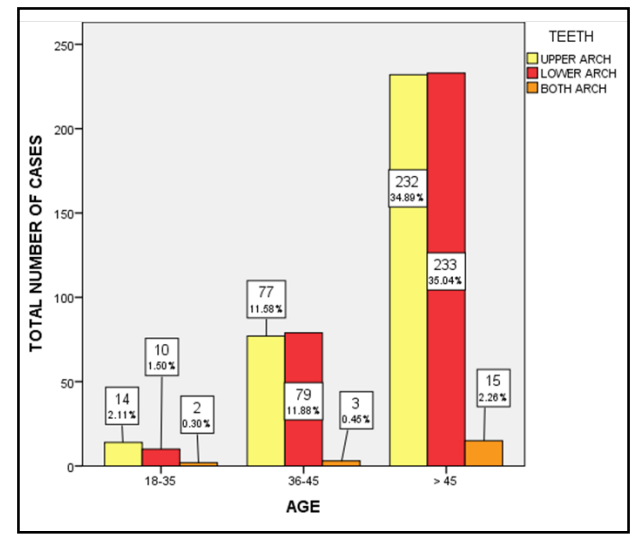


statistically nonsignificant. p-value higher than $0.05(>0.05)$ is not statistically significant and indicates strong evidence for the null hypothesis (Figure5).

From the above results, it is evident that tooth loss is more in 4060 age groups. The reason for the tooth can be of any reason, it could be due to trauma, surgery, periodontal and because of carious lesions. Some say it might be strongly due to caries [8]. Some say periodontitis as the most important factor at different age groups, after 35 years [27]. after 40 years [29]. 50 years [28] or 60 years of age [1].

The prosthetic management of the missing tooth will be replacing it with removable partial denture or an fixed partial denture. Recent advances include implants retained prosthesis.either screw retained or cement retained prosthesis.

Lucia (1979) stated that the most important consideration in occlusal reconstruction is CR. He stated that over $90 \%$ of normal healthy mouths have a dis- crepancy between CR and CO, and the most obvious reason for building an occlusion in CR is because it is prosthetically convenient.

Kaplan (1963) warned of the possibility of recording an inferior position of the condyles, employing the chin point guidance technique of CR recording, when exerting pressure on the chin area toward the condyle.

In literature, various methods have been described for registering centric relation. They can be classified as (1) static, (2) graphic, (3) physiologic or functional, and (4) cephalometric. Two of the most popular methods of registering centric relation are the intraoral Gothic arch (needle-point) tracing, and the wax recording procedure. Both of these methods have been criticized for their inaccuracies. Hanau'O pointed out the chief source of error in registering maxillomandibular relationships is the "resilient and like effect," Realeff, of the supporting tissues [20]. In order to minimize the influence of this factor, Hanaull and Wright" advocated that the registration of centric relations be made under minimum pressure or, when possible, with zero pressure. Wright even further suggested to use stabilized baseplates for more accurate registrations. It is axiomatic to state that registrations are no more accurate than the bases used in their execution [38]. Gysi, criticized the reliability of the wax recording techniques, said that "no two check bites obtained by wax or compound" were alike this is due to the uneven consistency of the occlusion rims, which further resulted in uneven pressures on the denture supporting tissues. Trapozzano" maintained that the wax recording method was the most accurate method because of the greater ability to equalize or centralize pressure with this technique [34].

Two factors which are of vital importance in the practice of prosthodontics will be considered in this discussion. They are (1) the physiologic vertical dimension and (2) the centric relation at the natural vertical dimension. The most commonly recommended method of determining centric relation is the Gothic arch (needlepoint) tracing proposed by Gysi in 1910. Since, that time, the tracing method has been both used and abused. Hanau* recommended use of the Gothic arch tracing but warned that it was a means of checking mandibular position and should be neither overrated or underrated [19] Granger insists that needle point tracing is not a reliable means of determining centric relation, since it is recorded in a horizontal plane only. He believes that centric relation should be considered as a vertical rotational relationship related to the hinge axis [17].

The prosthodontists who use some type of needle point tracing are not in accord regarding the relationship of the stylus to the tracing for determining centric relation. Swaggart wants some freedom of movement [33]. Brill claims that the retruded position of the mandible does not coincide with the maximum intercuspation in all persons [9]. Trapozzanoia persistently said that the only proper position and that position which is constant throughout life is the retruded unstrained relation [34]. Boos claims that 35 percent of 400 subjects had their "best" centric position 1 to 7 $\mathrm{mm}$. distal to the apex of the Gothic arch tracing [7]. Brown believes that the needle point tracing is unreliable and recommends repeated closures into wax under close observation $[7,10]$. Jamieson recommends an interocclusal record made with the tongue held at the posterior part of the upper baseplate [23]. Grass and Sharry found that the greatest variation of the apex position of needlepoint tracings was in a mediolateral position (18).

Mohamed et al. (1965) reported the variability of the Gothic arch tracing with an increase of vertical dimension. They used an extraoral tracing and indicated that by increasing vertical dimension the apex of the tracing relocates posteriorly and laterally. He concluded that the Gothic arch tracing is reliable if used at a given vertical dimension, of jaw separation under the same controlled condition, on the same individual and at the same settings.

Dawson $(1973,1979,1989)$ advocated the bimanual mandibular manipulation method for recording CR. He stated that CR is not the most posterior retruded position of the condyles; nor is it an unstrained position. Instead, he thought that CR could be defined as the most superior position the condyles can assume in the glenoid fossa.

\section{Conclusion}

Within the limitations of the study it can be concluded that most of the students have used pressure method for recording the centric relation, though it is not a reliable method. More reliable and accurate method has to be used for recording centric relation. This study shows that there was an increased incidence of edentulism either in maxillary or mandibular arch but not in both arches.

\section{References}

[1]. Agerholm DM, Sidi AD. Reasons given for extraction of permanent teeth by general dental practitioners in England and Wales. Br Dent J. 1988 Jun 11;164(11):345-8. Pubmed PMID: 3165009.

[2]. Ajay R, Suma K, Ali SA, Kumar Sivakumar JS, Rakshagan V, Devaki V, et al. Effect of Surface Modifications on the Retention of Cement-retained Implant Crowns under Fatigue Loads: An In vitro Study. J Pharm Bioallied Sci. 2017 Nov;9(Suppl 1):S154-S160. Pubmed PMID: 29284956.

[3]. Jain, Ashish R., Deepak Nallaswamy, Padma Ariga, and Dhanraj M. Ganapathy. "Determination of correlation of width of maxillary anterior teeth using extraoral and intraoral factors in Indian population: A systematic review." World J Dent 9 (2018): 68-75.

[4]. Ashok V, Nallaswamy D, Benazir Begum S, Nesappan T. Lip Bumper Prosthesis for an Acromegaly Patient: A Clinical Report. J Indian Prosthodont Soc. 2014 Dec;14(Suppl 1):279-82. Pubmed PMID: 26199531.

[5]. Ashok V, Suvitha S. Awareness of all ceramic restoration in rural population. Research Journal of Pharmacy and Technology. 2016 Oct 28;9(10):1691-3.

[6]. Basha FY, Ganapathy D, Venugopalan S. Oral hygiene status among pregnant women. Research Journal of Pharmacy and Technology. 2018 Jul 
31;11(7):3099-102.

[7]. Boos RH. Occlusion from rest position. The Journal of Prosthetic Dentistry. 1952 Sep 1;2(5):575-88.

[8]. Bouma J, Schaub RM, van de Poel F. Relative importance of periodontal disease for full mouth extractions in the Netherlands. Community Dent Oral Epidemiol. 1987 Feb;15(1):41-5. Pubmed PMID: 3467892.

[9]. Brill N. Reflexes, registrations, and prosthetic therapy. The Journal of Prosthetic Dentistry. 1957 May 1;7(3):341-60

[10]. Brown JC. Articulator mechanisms for inducing condyle migration. The Journal of Prosthetic Dentistry. 1954 Mar 1;4(2):208-10.

[11]. Calagna LJ. A comprehensive treatment rationale combining prosthodontics and periodontics. J Prosthet Dent. 1973 Nov;30(5):781-8. Pubmed PMID: 4589438.

[12]. Carroll JJ, Dawson D. Adaptive tracking control of a switched reluctance motor turning an inertial load. In1993 American Control Conference 1993 Jun 2 (pp. 670-674). IEEE.

[13]. Dawson PE. New definition for relating occlusion to varying conditions of the temporomandibular joint. J Prosthet Dent. 1995 Dec;74(6):619-27. Pubmed PMID: 8778387.

[14]. Duraisamy R, Krishnan CS, Ramasubramanian H, Sampathkumar J, Mariappan S, Navarasampatti Sivaprakasam A. Compatibility of Nonoriginal Abutments With Implants: Evaluation of Microgap at the Implant-Abutment Interface, With Original and Nonoriginal Abutments. Implant Dent. 2019 Jun;28(3):289-295. Pubmed PMID: 31124826.

[15]. Ganapathy D, Sathyamoorthy A, Ranganathan H, Murthykumar K. Effect of Resin Bonded Luting Agents Influencing Marginal Discrepancy in All Ceramic Complete Veneer Crowns. J Clin Diagn Res. 2016 Dec;10(12):ZC67ZC70. Pubmed PMID: 28209008.

[16]. Ganapathy DM, Kannan A, Venugopalan S. Effect of coated surfaces influencing screw loosening in implants: A systematic review and meta-analysis. World Journal of Dentistry. 2017 Nov;8(6):496-502.

[17]. Granger ER. Centric relation. The Journal of Prosthetic Dentistry. $1952 \mathrm{Mar}$ $1 ; 2(2): 160-71$

[18]. Grasso JE, Sharry J. The duplicability of arrow-point tracings in dentulous subjects. J Prosthet Dent. 1968 Aug;20(2):106-15. Pubmed PMID: 5242855.

[19]. Hanau RL. Dental engineering. J. Am. Dent. Assoe. 1922 Jul 1;9:595-609.

[20]. Hanau RL. The relation between mechanical and anatomical articulation. The Journal of the American Dental Association (1922). 1923 Aug $1 ; 10(8): 776-84$

[21]. International Academy of Gnathology. Glossary Committee (1979) The glossary of occlusal terms.

[22]. Ranganathan H, Ganapathy DM, Jain AR. Cervical and Incisal Marginal Discrepancy in Ceramic Laminate Veneering Materials: A SEM Analy- sis. Contemp Clin Dent. 2017 Apr-Jun;8(2):272-278. Pubmed PMID: 28839415.

[23]. Jamieson CH. A modern concept of complete dentures. The Journal of Prosthetic Dentistry. 1956 Sep 1;6(5):582-92.

[24]. Jyothi S, Robin PK, Ganapathy D. Periodontal health status of three different groups wearing temporary partial denture. Research Journal of Pharmacy and Technology. 2017 Dec 1;10(12):4339-42.

[25]. Kannan A, Venugopalan S. A systematic review on the effect of use of impregnated retraction cords on gingiva. Research Journal of Pharmacy and Technology. 2018 May 30;11(5):2121-6.

[26]. Lucia VO. A technique for recording centric relation. The Journal of Prosthetic Dentistry. 1964 May 1;14(3):492-505.

[27]. Ong G. Periodontal reasons for tooth loss in an Asian population. J Clin Periodontol. 1996 Apr;23(4):307-9. Pubmed PMID: 8739160.

[28]. Razak IA, Jaafar N, Nor GM. Age, sex and ethnic trends in tooth loss due to caries. Odontostomatol Trop. 1989 Dec;12(4):143-5. Pubmed PMID: 2638746.

[29]. Reich E, Hiller KA. Reasons for tooth extraction in the western states of Germany. Community Dent Oral Epidemiol. 1993 Dec;21(6):379-83. Pubmed PMID: 8306617.

[30]. Selvan SR, Ganapathy D. Efficacy of fifth generation cephalosporins against methicillin-resistant Staphylococcus aureus-A review. Research Journal of Pharmacy and Technology. 2016 Oct 28;9(10):1815-8.

[31]. Serrano PT, Nicholls JI, Yuodelis RA. Centric relation change during therapy with corrective occlusion prostheses. J Prosthet Dent. 1984 Jan;51(1):97105. Pubmed PMID: 6583394.

[32]. Subasree S, Murthykumar K. Effect of aloe vera in oral health-A review. Research Journal of Pharmacy and Technology. 2016 May 1;9(5):609.

[33]. Swaggart LW. Occlusal harmony in complete denture construction. The Journal of Prosthetic Dentistry. 1957 Jul 1;7(4):434-55.

[34]. Trapozzano, V. R. (1955) 'Occlusal records', The Journal of Prosthetic Dentistry, pp. 325-332. doi: 10.1016/0022-3913(55)90036-6.

[35]. Venugopalan S, Ariga P, Aggarwal P, Viswanath A. Magnetically retained silicone facial prosthesis. Niger J Clin Pract. 2014 Mar-Apr;17(2):260-4. Pubmed PMID: 24553044.

[36]. Vijayalakshmi B, Ganapathy D. Medical management of cellulitis. Research Journal of Pharmacy and Technology. 2016 Nov 28;9(11):2067-70.

[37]. Woelfel JB. New device for accurately recording centric relation. J Prosthet Dent. 1986 Dec;56(6):716-27. Pubmed PMID: 3464753.

[38]. Wright WH. Use of intra-oral jaw relation wax records in complete denture prosthesis. The Journal of the American Dental Association. 1939 Apr $1 ; 26(4): 542-57$. 